\title{
An observational study on awareness of teratogenic drugs among undergraduate students from two medical institutes of Central India
}

\author{
Devendra Singh Kushwah ${ }^{1 *}$, Beenu Kushwah ${ }^{2}$
}

${ }^{1}$ Department of Pharmacology, GR Medical College, Gwalior, Madhya Pradesh, India

${ }^{2}$ Department of Obstetrics and Gynecology, SS Medical College, Rewa, Madhya Pradesh, India

Received: 11 July 2021

Revised: 21 August 2021

Accepted: 23 August 2021

\section{*Correspondence:}

Dr. Devendra Singh Kushwah,

Email: dev_singh433@yahoo.com

Copyright: (C) the author(s), publisher and licensee Medip Academy. This is an open-access article distributed under the terms of the Creative Commons Attribution Non-Commercial License, which permits unrestricted non-commercial use, distribution, and reproduction in any medium, provided the original work is properly cited.

\begin{abstract}
Background: Teratogenicity caused by drugs can be avoided to major extent just by creating more awareness about rational use of drugs among treating doctors. Deleterious effects of a drug upon developing foetus are directly related with the stage of embryological development at the time of exposure. Attainment of right knowledge at right time about teratogenicity of a particular drug is very crucial which requires more awareness among general doctors in a country like India where most of the pregnant females are manged by these doctors only in peripheral regions. Present study was an observational study to assess basic knowledge of undergraduate medical students regarding teratogenicity in order to make necessary changes in existing mode of training of this particular topic.

Methods: Present study was a questionnaire based cross sectional observational study to assess basic knowledge of undergraduate medical students regarding different aspects of teratogenicity. It included 250 students of two medical colleges of central India.

Results: Out of 250 students 146 students reported on time. Maximum students (71\%) were aware about the teratogenicity property of certain harmful drugs. Although $90 \%$ of students knew that early first trimester is the most susceptible time, only $21 \%$ could state the importance of doing counselling regarding use of drugs even before pregnancy.

Conclusions: Based on the findings of present study it is obvious that more emphasis should be put on improving knowledge about teratogenic drugs during early years of medical training in order to bring about necessary changes in existing practices of treating doctors.
\end{abstract}

Keywords: Teratogenicity, Medical students, Congenital malformations

\section{INTRODUCTION}

A teratogen is an agent that can affect the development of the embryo or fetus adversely. Teratogens may halt the pregnancy altogether or cause a birth defect. There are many types of teratogens viz radiation, maternal infections, chemicals, and drugs. ${ }^{1}$ The famous thalidomide tragedy which resulted in phocomelia and other major congenital malformations among the babies born to mothers who consumed Thalidomide during first trimester for nausea and vomiting of pregnancy, was the first reported teratogenic event caused by a drug. ${ }^{2}$ Thalidomide tragedy gave rise to development of interest in scientists to further study this area in detail. Despite the fact that much research has been done in this area, exposure to teratogenic drugs remains a major cause of congenital malformations and long-term disabilities in affected fetus. Teratogenic drugs can affect developing fetus at various stages of intrauterine life, most susceptible being the period of organogenesis i.e. from $3^{\text {rd }}$ week to $8^{\text {th }}$ week of intrauterine life, nevertheless these drugs can affect a fetus beyond 8 weeks also as development and 
maturation of many organs continues throughout the pregnancy. $^{3}$

As per one study from Europe about $86 \%$ pregnant women are exposed to $>1$ drug and at least $1 \%$ birth defects are a result of teratogenic drug use in pregnancy., ${ }^{4,5}$ On other side pregnant women themselves decided to terminate their otherwise wanted pregnancy because of their wrong perception of even safe drugs like antihistamines most important reason being lack of effective counselling by the treating doctor. ${ }^{6}$

Worldwide a significant proportion of pregnancies are unplanned. ${ }^{7,8}$ With medical advances more of these women with chronic medical conditions are getting pregnant and need to continue their medication, therefore treating doctor needs to be very well aware about the teratogenicity of drugs. ${ }^{9,10}$ During recent times use of herbal and natural drugs has become very common during pregnancy without much data available regarding teratogenicity of these drugs. ${ }^{11}$ India having a high birth rate, contributes to a large number of congenitally malformed babies. ${ }^{12}$

Most of the Indian pregnant females can't access a secondary or tertiary care institute during initial period of pregnancy and generally are taken care by a general physician, who may not have a very good knowledge regarding rational drug prescription in pregnancy. In our undergraduate curriculum also topic of teratogenicity doesn't get due space, therefore there is a need to increase awareness regarding teratogenic drugs during undergraduate training itself. In present study we included second professional students from two different medical colleges of Madhya Pradesh, to assess their knowledge regarding teratogenic drugs as a part of their second professional pharmacology class on teratogenicity.

\section{METHODS}

Present study was a questionnaire-based cross-sectional observational study which was carried out among students of second professional on a single date from two different medical colleges of Madhya Pradesh, India. Study subjects were second professional students of these two medical colleges. This study was done over a period of one week from 01 June 2021 to 07 June 2021. The students were explained about the parts of questionnaire and were asked to submit it back. Total 250 students were approached for the same out of which 146 students responded on time. The questionnaire comprised of some very basic questions related with teratogenicity caused by drugs. The assessment of the performance of the students regarding the knowledge of various aspects of teratogenicity was done.

Appropriate statistical tests were applied and results were derived accordingly. Ethical approval was obtained from head of both the institutes. Questionnaire (Table 1) which was used is as following:
Table 1: Questionnaire.

\begin{tabular}{|c|c|}
\hline Sr. no. & Questionnaire \\
\hline 1. & Are you aware of the term teratogen? \\
\hline a. & Yes \\
\hline b. & No \\
\hline 2. & Can drugs cause teratogenicity? \\
\hline a. & Yes \\
\hline b. & No \\
\hline 3. & $\begin{array}{l}\text { Do you think that teratogenicity due to } \\
\text { drugs can occur during all the three } \\
\text { trimesters? }\end{array}$ \\
\hline a. & Yes \\
\hline b. & No \\
\hline 4. & $\begin{array}{l}\text { Can you name US-FDA fetal risk } \\
\text { categories of teratogenic drugs? }\end{array}$ \\
\hline a. & Yes \\
\hline \multirow[t]{2}{*}{ b. } & No \\
\hline & If yes, name it: \\
\hline 5. & Can you name first drug teratogen? \\
\hline a. & Yes \\
\hline \multirow[t]{2}{*}{ b. } & No \\
\hline & $\begin{array}{l}\text { If yes, name it and the associated anomaly } \\
\text { it caused in fetus: }\end{array}$ \\
\hline 6. & Can you name two teratogenic drugs? \\
\hline a. & Yes \\
\hline \multirow[t]{2}{*}{ b. } & No \\
\hline & If yes, names: \\
\hline 7. & $\begin{array}{l}\text { Are you aware of the results/outcomes of } \\
\text { teratogenicity? }\end{array}$ \\
\hline a. & Yes \\
\hline b. & No \\
\hline 8. & $\begin{array}{l}\text { Do you think that a history of teratogenic } \\
\text { drug intake should be elicited from all } \\
\text { pregnant females? }\end{array}$ \\
\hline a. & Yes \\
\hline b. & No \\
\hline 9. & $\begin{array}{l}\text { Which time of pregnancy is most } \\
\text { appropriate to counsel a lady about } \\
\text { teratogens? }\end{array}$ \\
\hline a. & $1^{\text {st }}$ trimester \\
\hline b. & $2^{\text {nd }}$ trimester \\
\hline c. & $3^{\text {rd }}$ trimester \\
\hline d. & Before pregnancy \\
\hline 10. & $\begin{array}{l}\text { Which time of intrauterine life is most } \\
\text { susceptible to teratogens }\end{array}$ \\
\hline a. & First 8 weeks \\
\hline b. & Last 4 weeks \\
\hline c. & Throughout the pregnancy \\
\hline
\end{tabular}

\section{RESULTS}

Response rate was found to be $58 \%$ within the stipulated time period, although it reached up to $87 \%$ after 24 hours. Statistical analysis was done only of those responses which were submitted within the time limit. Table 2 summarises responses of students which could be answered in yes or no. It can be seen from Table 2 that maximum students knew about the term teratogen and drugs being a major 
cause of teratogenicity. A major proportion of students was also aware about the FDA category of drugs. Figure 1 and 2 depict responses to basic questions regarding teratogenicity which were answered as yes or no while Figure 3 and 4 depicts responses regarding descriptive questions. It is clear from Figure 3 and 4 that although students were aware that maximum chances of causing teratogenicity by a drug are in first trimester but their knowledge regarding drug's ability to cause teratogenicity during periconception period was poor and maximum students could not describe about the value of preconception counselling regarding teratogenicity caused by drugs.

Table 2: Responses towards awareness of teratogenicity.

\begin{tabular}{|c|c|c|}
\hline Questions & Yes & No \\
\hline Are you aware of the term teratogen? & 141 & 5 \\
\hline Can drugs cause teratogenicity & 103 & 43 \\
\hline $\begin{array}{l}\text { Do you think teratogenicity due to } \\
\text { drugs can occur during all trimesters? }\end{array}$ & 83 & 63 \\
\hline $\begin{array}{l}\text { Can you name the five fetal risk } \\
\text { categories? }\end{array}$ & 104 & 42 \\
\hline Can you name first drug teratogen? & 94 & 52 \\
\hline $\begin{array}{l}\text { Can you name any two teratogenic } \\
\text { drugs? }\end{array}$ & 123 & 23 \\
\hline $\begin{array}{l}\text { Do you know the results/outcome of } \\
\text { teratogenicity? }\end{array}$ & 84 & 62 \\
\hline $\begin{array}{l}\text { Do you think that a history of } \\
\text { teratogenic drug intake should be } \\
\text { elicited from all pregnant females? }\end{array}$ & 113 & 33 \\
\hline
\end{tabular}

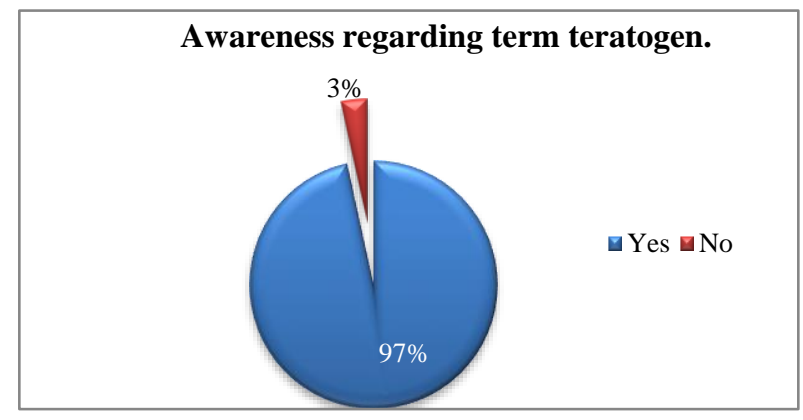

Figure 1: Awareness regarding term teratogen.

Can drugs cause teratogenicity?

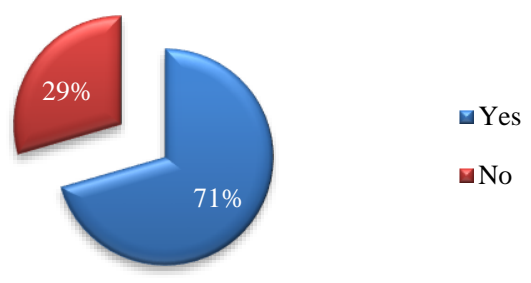

Figure 2: Can drugs cause teratogenicity.

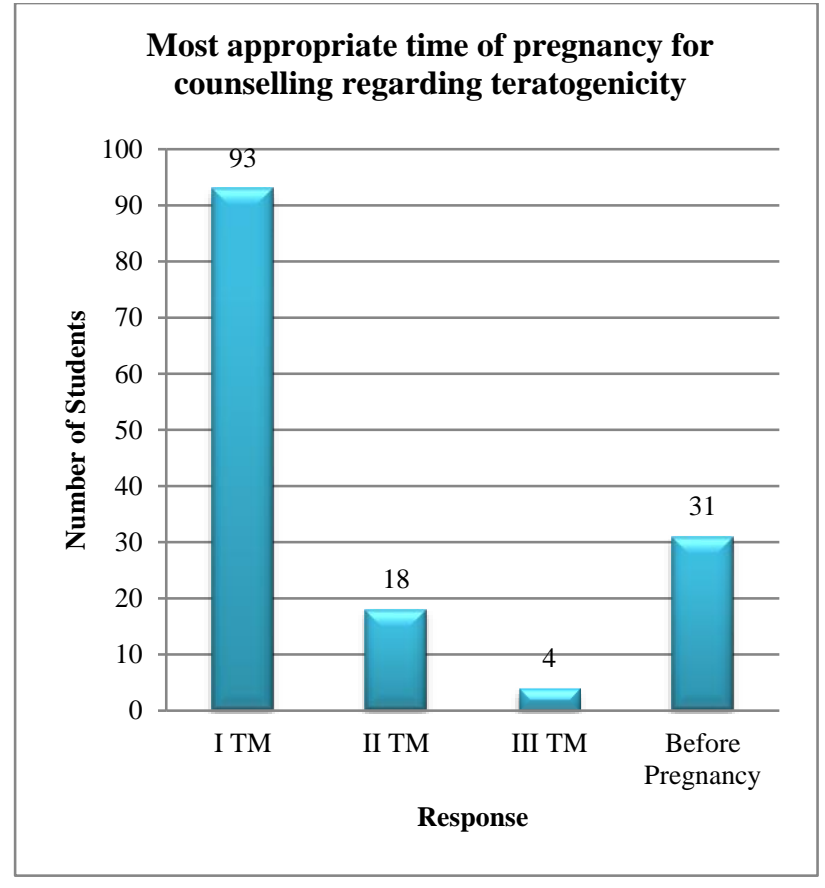

Figure 3: Most appropriate time of pregnancy for counselling regarding teratogenicity.

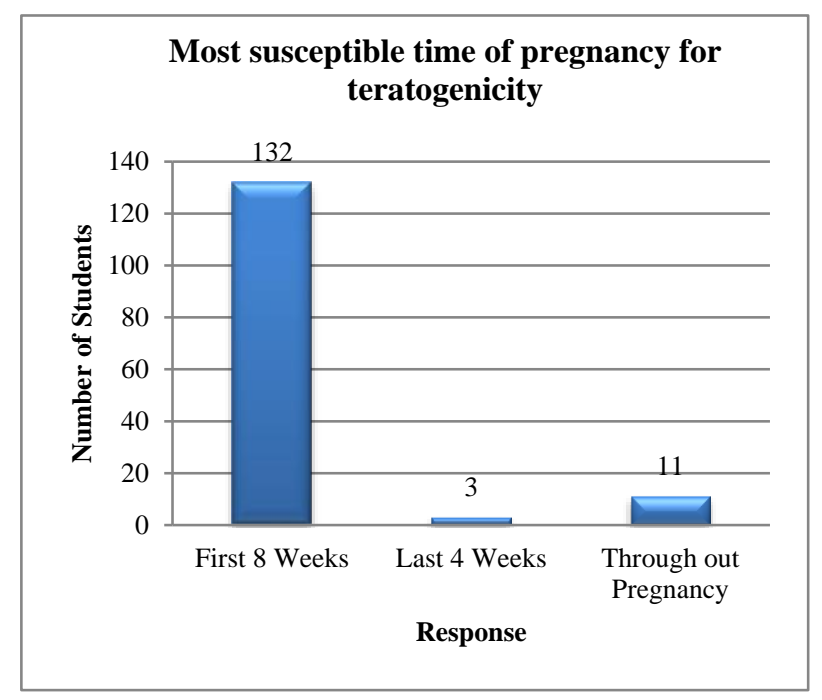

Figure 4: Most susceptible time of pregnancy for teratogenicity.

\section{DISCUSSION}

Awareness regarding teratogenicity among medical students right from their training period is very important in order to reinforce the habit of asking relevant drug history from all reproductive age group and pregnant women because these defects are preventable in most of the cases and also the impact of malformations affects not only the patients but also their families. ${ }^{13}$ Hence, it is the need of the hour to make students aware of this important issue. In the present study, 250 second professional medical students were approached to participate, out of which 146 students responded on time. In the present 
study, $96 \%$ students were aware of the term teratogen and maximum $(71 \%)$ could tell drugs are important teratogens. Most of the students $(57 \%)$ were aware that teratogenicity due to drugs can occur during all the three trimesters.

Although this number was lesser which is due to the fact that generally it is considered that a drug is teratogenic only during the 1 st trimester as organogenesis occurs during this period only. More awareness is needed regarding creating awareness about developmental and biochemical abnormalities that can occur, even when teratogenic drug exposure occurs during the 2nd and 3rd trimesters. These results are consistent with the previous published studies. ${ }^{14,15}$ Surprisingly most of the students (71\%) knew about all the five FDA risk categories. Furthermore, $64 \%$ of students were able to mention the names of two teratogenic drugs correctly. However, $57 \%$ students could exactly explain about the type of malformation associated with certain group of drugs. $77 \%$ of students knew the value of eliciting drug intake history in pregnant women. This shows the awareness of students regarding value of this important information to be acquired from a pregnant lady.

$64 \%$ students thought that this history of drug intake is to be asked during first trimester only while only $21 \%$ thought that it is important to ask this history even before pregnancy, this finding emphasizes upon creating more awareness regarding preconception counselling among students right from their training time. When students were asked about the most susceptible time for teratogen to affect the fetus, majority $(90 \%)$ thought that it is initial 8 weeks of intrauterine life, which is correct.

The limitations of the present study were that of a small sample size of students, nevertheless sample was quite mixed as students belonged to two different students. We are planning same study among final year medical students in near future to assess impact of training in improving their knowledge regarding teratogenicity with a larger sample size.

\section{CONCLUSION}

In the present study, it was found that more effective training is required during undergraduate course itself to create proper awareness among medical students about the teratogenicity of drugs. The medical students should be taught this topic by including more case discussions related with teratogenicity during their clinical practice to inculcate the habit of thinking about possible intake of teratogenic drug by a pregnant lady whenever they come across an antenatal case.

Funding: No funding sources Conflict of interest: None declared

Ethical approval: The study was approved by the Institutional Ethics Committee

\section{REFERENCES}

1. Rang HP, Dale MM, Ritter JM, Fowler RJ. The Harmful effects of drugs. Rang and Dale's pharmacology. 6th ed. Edinburgh, UK: Churchill Livingstone; 2007: 757-758.

2. McBride WB. Thalidomide and congenital abnormalities. Lancet. 1961;21358.

3. Bisht M, Dhasmana DC. Teratagenecity and maternogenicity. Myths and facts. RJPBCS. 2014;5:452-69.

4. Clementi M, Gianantonio E, Ornoy A. Teratology information services in Europe and their contribution to the prevention of congenital anomalies. Community Genet. 2002;5(1):8-12.

5. Webster WS, Freeman JA. Is this drug safe in pregnancy? Reprod Toxicol. 2001;15(6):619-29.

6. Koren G, Pastuszak A. Teratogen Information Service. Maternal fetal toxicology: a clinician's guide. 2nd ed. New York, NY: Marcel Dekker; 1994: 683705 .

7. Einarson A, Bailey B, Jung G, Spizzirri D, Baillie M, Koren G. Prospective controlled study of hydroxyzine and cetirizine in pregnancy. Ann Allergy Asthma Immunol. 1997;78(2):183-6.

8. WHO. Unsafe abortion: global and regional estimates of the incidence of unsafe abortion and associated mortality in 2008. 6th ed. Geneva: WHO; 2011.

9. Guttmacher Institute. Facts on abortion and unintended pregnancy in Asia. Available at: http://www.guttmacher.org/pubs/IB_AWWAsia.pdf. Accessed on 02 July 2021.

10. Bianca S. Drug use during pregnancy: are risk classifications more dangerous than the drugs?. Lancet. 2003;362(9380):329.

11. Nordeng H, Ystrøm E, Einarson A. Perception of risk regarding the use of medications and other exposures during pregnancy. Eur J Clin Pharmacol. 2010;66(2):207-14.

12. Andrade SE, Gurwitz JH, Davis RL, Chan KA, Finkelstein JA, Fortman K, et al. Prescription drug use in pregnancy. Am $\mathrm{J}$ Obstet Gynecol. 2004;191(2):398-407.

13. Sharma R. Birth defects in India: Hidden truth, need for urgent attention. Indian $\mathbf{J}$ Hum Genet. 2013;19(2):125-9.

14. Bánhidy F, Lowry RB, Czeizel AE. Risk and benefit of drug use during pregnancy. Int $\mathrm{J}$ Med Sci. 2005;2(3):100-6.

15. Yawn B, Knudtson M. Treating asthma and comorbid allergic rhinitis in pregnancy. $\mathrm{J}$ Am Board Fam Med. 2007;20(3):289-98.

16. Yankowitz J, Niebyl JR. Drug Therapy in Pregnancy. 3rd ed. United States: Lippincott Williams \& Wilkins; 2001.

Cite this article as: Kushwah DS, Kushwah B. An observational study on awareness of teratogenic drugs among undergraduate students from two medical institutes of Central India. Int J Basic Clin Pharmacol 2021;10:1182-5. 